\title{
The Relationship between Infertility and Nutrition
}

\author{
Sanlier $\mathrm{N}^{*}$, and Yorusun $\mathrm{TO}^{2}$
}

${ }^{1}$ Lokman Hekim University, Faculty of Health Sciences, Department of Nutrition and Dietetics, Ankara, Turkey

${ }^{2}$ Gazi University, Faculty of Health Sciences, Department of Nutrition and Dietetic, Ankara, Turkey

${ }^{*}$ Corresponding author: Sanlier N, Lokman Hekim University, Faculty of Health Sciences, Department of Nutrition and Dietetics, Ankara, Turkey, Tel: 5325855944, E-mail: nevintekgul@gmail.com

Citation: Sanlier N, Yorusun TO (2018) The Relationship between Infertility and Nutrition. J Nutr Health Sci 5(2): 207. doi: 10.15744/2393-9060.5.207

Received Date: April 17, 2018 Accepted Date: May 29, 2018 Published Date: June 02, 2018

\begin{abstract}
The problem of infertility could arise from the woman, the man or both of them and sometimes it could stem from without a reason. The reasons of male infertility could be varicocele, idiopathic infertility, obstruction, undescended testis, immunological mechanisms, ejaculation disorder, testicular insufficiency, medicine-radiation effect, endocrine disorders such as diabetes, excessive consumption of alcohol, smoking and environmental toxins such as pesticides and lead. It is also believed that societies, obesity, lack of nutrition and ways of spending time for example excessive use of mobile phones, laptop computers and sauna, etc., as for women, age, smoking, excessive consumption of alcohol, having a skinny or overweight body and having been exposed to physical or emotional stress resulting in amenorrhea might be the causes of infertility. The increase in infertility prevalence draws attention to the effects of factors such as life style, nutritional habits and environmental factors. Male infertility emerges from mostly as a result of the relationship between oxidative stress and antioxidants, whereas, female infertility results from mostly as a result of insulin resistance and the effects of PCOS and BMI. Therefore, in this review, the relationship between nutrition and infertility which is commonly seen in men and women is studied.
\end{abstract}

Keywords: Infertility; Female; Male; Nutrition; Nutrient

\section{Introduction}

Infertility is a reproduction disease when a woman is unable to get pregnant despite having unprotected sex at least for 12 months [1]. $25 \%$ of couples fail to achieve pregnancy in one year's time, $15 \%$ of them get medical help and less than $5 \%$ of them can't have a child [2].

Pregnancy occurs when the egg freed from one of the female's ovaries is united with the male sperm and gets fertilized, and then the fertilized egg is carried to the uterus by fallopian tubes and hangs on there. Infertility occurs when a problem arises in one or more of these steps [3]. Has stated that nearly 186 million women in developing countries are infertile [1]. However, infertility is not only a female-based problem. While $45 \%$ of the problem originates from women, $30 \%$ of it originates from men. $20 \%$ of it originates from both genders and 5\% of the problem originates although there is no reason [4]. Infertility could also develop as a result of life style, nutritional habits and environmental factors [5]. Therefore, in this review, the effect of the factors related to nutrition which affect infertility is studied.

\section{Methodology}

Scientific information on the subject was obtained from the literature through databases such as PubMed, Science Direct and Google Scholar. The reference articles were obtained from databases using key words such as 'female's and male's infertility, nutrition, nutrient, health effects/benefical effects/health benefits to collect existing information. The sub-references of the selected articles via the keywords were reached and these articles were examined as well. In studies on infertility, primarily clinical human studies, laterly animal studies have been viewed. The research, meta-analyzes and reviews have been the basis for the current work.

\section{Male Infertility}

Male infertility could develop as a result of varicocele, idiopathic-unexplained infertility, obstruction, undescended testis, immunological mechanisms, ejaculation disorder, testicular insufficiency, medicine-radiation effect (treatments of chemotherapy and radiotherapy, use of steroids, illegal drug use), endocrine disorder (diabetes), unhealthy habits such as excessive consumption of alcohol, smoking and environmental toxins such as pesticides and lead $[3,6]$. Over $50 \%$ of the infertility cases in men have unknown etiology and they are classified as idiopathic [7]. It is believed that, especially in Western societies, some changes in 
the way of living (obesity, lack of nutrition) and ways of spending time (mobile phones, laptop computers, sauna, etc.) affect the reproductive health of men negatively [8]. Most of the effects of these reasons on cellular level emerge from reactive oxygen species (ROS) or complete their pathology by the help of ROS production [6]. Infertility usually affects the sperm count (concentration) of the semen, its motility and morphology [3]. WHO (2010) determined male fertility reference values as: sperm concentration $\geq 15^{\star} 106 / \mathrm{mL}$, vitality $\geq \% 58$, progressive motility $\geq \% 32$ and morphologically normal spermatozoa $\geq \% 4$. In the analysis of the results of infertile men, low sperm count (oligospermia), reduced motility (asthenozoospermia) and too much sperm with abnormal morphology (teratozoospermia) were found. These anomalies usually occur at the same time and this is called oligoastheno-teratozoospermia (OAT) syndrome $[1,2]$.

\section{The Relationship of Body-Mass Index and Infertility}

As a result of studies done on infertility in humans and animals, it has been found that the more body-mass index (BMI) increases in men, the more the parameters such as the quality of sperm, sperm motility and testosterone level etc., decreases, which leads to infertility [5,9-12]. A research conduct on 225 infertile men showed that $40 \%$ of the participants are overweight [9]. In the study of Pauli et al. (2008), testosterone, follicle stimulating hormone (FSH) and inhibin B showed negative correlation with BMI; however, no relationship was determined with semen parameters [11]. The increase in fatty tissues causes the testosterone to turn into estrogen and decreases the amount of testosterone in the blood, sperm count and quality. Besides, when the rate of fat increases around the testes, the heat in that part of the body also increases and this leads to a decrease in the production and quality of sperms [5,8]. In two meta-analysis researches involving 13077 and 9779 men who consulted to a fertility clinic and are from the general population, it was found out that as BMI increases, the risk of azoospermia and oligozoospermia also increases [13,14]. In infertile individuals, obesity might lead to outcomes such as the transformation of sperm DNA, fertilization degeneration, the transformation of embryo and blastocyst, a decrease in the rate of insemination and an increase in the possibility of miscarriage [15]. In another study that analyzed the relationship between BMI and DNA fragmentation index and in which a normal group is used as a reference, DFI (DNA Fragmentation Index) is found 20\%, 30\% more in overweight and obese individuals, respectively [16].

\section{Nutritional Pattern and Infertility}

A high carbohydrate diet is one of the most common features of Asian society. A positive correlation has been found between the consumption of too much carbohydrate and abnormal sperm motility and progressive motility. Nevertheless, a negative relationship has been discovered between sperm concentration and morphology in the Western diet [17]. In a study in which 7282 men were analyzed, too much consumption of the Western diet was proved to result in the decrease of sperm count and normal sperm morphology. Excessive consumption of sweet junk food and drinks were reported to cause the sperm count to decrease [18]. In addition, the energy percentage of a diet taken from saturated fat being over $10 \%$ was claimed to lead to a decrease in the sperm count. Individuals consuming saturated fat frequently were discovered to have $38 \%$ lower sperm concentration and $41 \%$ lower sperm count compared to the ones who consume it less $[5,19]$. As polyunsaturated fatty acids (PUFA) are important components of membrane structures of sperm cells and because of their antioxidant features, they play an important role in a successful fertilization by protecting the sperm cells from oxidative stress [5,20]. Also the PUFA are necessary for the plasma membrane fluidity and normal physiological function of sperm. Polyunsaturated fatty acids play an important role in ion transport and sperm membrane fluidity, therefore oxidation of sperm membrane PUFA by oxidants (ROS) can cause deficiency of membrane function and sperm death [21]. In a study which analyzed the relationship between sperm and blood PUFA concentration and sperm parameters, a positive relationship was found between sperm and blood omega- 3 fatty acid concentrations and sperm concentration, its motility and morphology; whereas a negative relationship was found between them and omega-6 fatty acids [22]. Fatty acid composition of the spermatozoa may be an important determinant of fertility [22]. In a study concluded that $\omega-3$ fatty acid had favorable effects in rat testis tissue by preventing oxidative damage and increasing the level of testosterone [23].

\section{The Relationship between Some Vitamins and Infertility}

Antioxidant vitamins (vitamins A, C and E): Oxidative stress is the increase of the rate of cellular damage triggered by oxygen and oxygen-based oxidants known as reactive oxygen species. Some stressful situations such as chronic diseases, aging, being exposed to toxins, physical injuries and being exposed to certain types of nutrition may speed up oxidative process and cause cell damage [24]. Lately, oxidative stress has become one of the most common causes of male infertility. Normally in male reproductive organs, there is a balance between reactive oxygen production and antioxidant scavenging activities. Stress develops when the balance between the production of reactive oxygen species and antioxidant defense deteriorates [25]. As sperms consist of polyunsaturated fatty acids in high concentrations and due to their ability to create reactive oxygen species (ROS) such as superoxide anion and hydrogen peroxide at the beginning, they are inclined to peroxidative damage [26]. Lipid peroxidation in spermatozoa and semen is evaluated by malondialdehyde concentrations. Oligoasthenozoospermic and asthenozoospermic individuals have twice more sperm MDA concentration than normal people [27]. Vitamins A, C and E (carotenoids, a-tocopherol, and ascorbic acid) are able to keep the prooxidant-antioxidant balance and by preventing the oxidative damage in the sperm DNA, they maintain the genetic integrity of sperm cells $[5,26]$. In another study, it was found that there is a positive relationship between the intake of vitamin $\mathrm{C}$ and $\beta$-carotene and sperm count, concentration and the total progressive motile sperm count; between the intake of vitamin 
$\mathrm{E}$ and progressive motile sperm count $[5,28]$. As vitamin $\mathrm{C}$ supplement has testosterone increasing and antioxidant effects, it is claimed that it may also be able to cure stress-based infertility [25]. In a controlled study done on rats, a significant decrease was determined in sperm count, motility and testicular weight in the stress group. It was stated that consuming medium (20 mg/kg) and high $(30 \mathrm{mg} / \mathrm{kg})$ doses of vitamin C causes significant increases in sperm count and motility. It was reported that high dose of vitamin C supplement affects hypothalamic-pituitary-testicular axis and rises the level of testosterone level [25]. In a study done on asthenozoospermic and oligoasthenozoospermic men, after being given daily $300 \mathrm{mg}$ of vitamin E supplement for 6 months, it was reported that their MDA concentration decreased, less lipid peroxidation developed in their sperms,as a result,their sperm motility and the rate of pregnancy resulting in birth increased [27].

Folate: Folate, is an essential vitamin for the DNA found in green leafy vegetables, transfer RNA and protein synthesis. As DNA synthesis is an important part of spermatogenesis, folate is of high importance for the continuity of fertility [29]. The folate which is obtained through food should be converted from polyglutamate into monoglutamate form so as to be absorbed in jejunum. This conversion is only possible by the help of gamma-glutamyl hydrolase enzyme. Zinc also plays an important role in folate metabolism as it is also found in the structure of this enzyme [30]. For this reason, in studies analyzing the effect of folate on sperm parameters, folate is usually used with zinc supplement [29,31]. For instance, infertile men who get a supplement of 5 mg of folic acid and $66 \mathrm{mg}$ of zinc sulfate supplement daily were found to have an increase of $74 \%$ in their total normal sperm count at the end of the treatment [29]. In another study done on fertile and infertile men, after 26 weeks of use of $5 \mathrm{mg}$ of folic acid and $66 \mathrm{mg}$ of zinc supplement daily, an increase in the sperm count of infertile men was detected, whereas it was not likewise in fertile men [31]. Men who consume $700 \mu \mathrm{g}$ or more folate daily are likely to have sperm DNA anomalies 30\% less than those who consume less than $700 \mu \mathrm{g}$ of folate daily [32]. However, it was also suggested in another study conduct on oligoasthenoteratozoospermic infertile men that daily consumption of $5 \mathrm{mg}$ of folic acid and $220 \mathrm{mg}$ of zinc sulfate for 16 weeks didn't improve the sperm quality [33].

Coenzyme Q10 (ubiquinol): Coenzyme Q10 is a vitamin-like substance which fat soluble and it is found in eukaryotic cells as it plays a role in mitochondrial respiratory chain [34]. In studies done on CoQ10, it was stated that CoQ10 supplement used in the treatment of male infertility increased sperm concentration and motility [35-39]. Infertile men between the ages of 20-40 who used $150 \mathrm{mg}$ of ubiquinol daily as a treatment for 6 months were reported to have $53 \%$ increase in their sperm count and $26 \%$ increase on their sperm motility. Except for the total motility, rapid progressive motile sperm count increased 41\% [39]. Follicle stimulating hormone and luteinizing hormone at low levels are being related to better spermatogenesis. An increase in the level of inhibin B reflect the functionality of sertoli cells [36]. The supplement of 200-300 mg of ubiquinol for 26 weeks was determined to have improved the sperm quality, consentration, motility and morphology; decrease the levels of serum follicle stimulating hormone and increase the levels of inhibin B [35,36,38]. In another study, it was stated that after the use of $600 \mathrm{mg}$ of CoQ10 for 12 months, sperm quality and pregnancy rates were reported to have increased [36].

\section{The Relationship of Certain Minerals and Infertility}

Selenium: Selenium is essential for testosterone biosynthesis as well as the standard development of sperms and their forms. Testicular tissues usually consist of high concentrations of selenium as glutathione peroxidase. In addition, this shows the relationship between selenium, sperm quality and male infertility. Since glutathione peroxidase is the main determiner of the sperm's middle piece structure, it is responsible for the protection of sperm cells from oxidative DNA injuries. By supplementing $400 \mathrm{mg}$ of vitamin $\mathrm{E}$ and $200 \mu \mathrm{g}$ of selenium, it was found that the levels of MDA decreased whereas sperm motility [40]. In an observational study carried out on infertile men between the ages of 20-45, after being supplemented 400 IU of vitamin E and $200 \mu \mathrm{g}$ of selenium for 100 days, sperm motility and morphology was reported to have increased $52,6 \%$ and as a result of a combined treatment of vitamin E and selenium, pregnancy was stated to have increased 10,8\% [41]. The studies conducted on infertile men prove that a supplement of selenium for at least 3 months increase the semen quality and an additional supplement of N-Acetyl Carnitine increases the testosterone level in addition to semen quality $[35,41,42]$. However, there are also studies that suggest selenium alone is not efficient by itself in the treatment of infertility. For example, although selenium concentrations increases in semen as a result of a supplement of 200-300 mg of selenite per day, by an intake of selenium yeast or an intake of high selenium with a diet, it was reported that it had no positive effects on sperm features or activities [43].

Zinc: The concentration of zinc in human semen plasma is more in quantity than other tissues [21]. Zinc improves the quality of sperm by the help of its antioxidant and antiapoptotic features. Besides its DNA transcription, its acting as a cofactor of the metalloenzymes taking part in protein synthesis is significant for sperm production [44]. It plays an important role on testis development, physiological functions of the sperm, by decreasing its level, which causes hypogonadism, decreased testis size, underdeveloped secondary sex characteristics and atrophy of the seminiferous tubes. Insufficient intake is claimed to damage the antioxidant defense system and could be an important risk factor in oxidant oscillation and it is effective on sperm cells being prone to oxidative damage [21]. Oral zinc supplement in idiopathic asthenozoospermic or oligospermic men is proven to affect sperm count, motility and morphology positively [26]. In a study which analyzed the semen samples of fertile and infertile male smokers and non-smokers, it was found that in the fertile group whether they are smokers or not, their zinc level was significantly high. Semen zinc levels are reported to be positively correlated to sperm count and their normal morphology [38]. 


\section{Other Nutritional Elements}

Caffeine (1,3,7- Trimethylxanthine): Coffee, tea, chocolate, some soft drinks such as cokes, which contain caffeine, are consumed in high amounts daily in industrial societies. Especially the consumption of fizzy drinks and cokes among children and adults is getting more and more each day [45]. Studies about caffeine consumption and semen quality contradict with each other. Some of them suggest that caffeine consumption doesn't affect semen quality and others suggest that it decreases semen quality [4548]. In a study which analyzed daily caffeine consumption of 2.554 men and their sperm quality, it was suggested that there is no relationship between medium (201-800 mg) or low level (101-200 mg) of caffeine intake and semen quality, whereas, there is a negative relationship between high caffeine consumption, sperm concentration and total sperm count. Especially with the consumption of cokes and energy drinks, a significant decrease was detected in sperm quality. Men who consume plenty of cokes have $40^{\star} 106 / \mathrm{mL}$ of sperm count, however, the ones who consume none have $181^{\star} 106 / \mathrm{mL}$ sperm count [45,49]. It was reported that this situation is not related to caffeine consumption only; it may be related to other unhealthy nutritional habits, such as BMI and other factors [45].

Carnitine: Carnitine is found in the metabolism as L-carnitine (LC) or acetyl carnitine (LAC) and it plays an important role in $\beta$-oxidation for cellular energy of long chain fatty acids in lipid metabolism. Besides, it protects the cellular membrane and the DNA from the damage of free oxygen radicals. As it is in charge of the energy metabolism to be used by sperms, it affects sperm motility, maturation and sperm formation process [50]. In a meta-analysis study LC and/or LAC supplemented patients were proved to have significant differences in the rates of pregnancy, total sperm motility, progressive sperm motility and abnormal sperm cells, whereas no difference was found out between sperm concentration and semen volume [51]. $3 \mathrm{~g}$ of LAC, $2 \mathrm{~g}$ of LC and $1 \mathrm{~g}$ of LAC daily supplemented infertile men were reported to have increased their sperm motility. Individuals who received combined treatment were stated to have differences in their sperm parameters and the most significant difference was seen in individuals with low primary sperm motility [52].

N-Acetylcysteine (NAC): N-acetylcysteine is an amino acid made up of L-cysteine which exists naturally and it is a glutathione precursor having antioxidant features. NAC increases glutathione concentration which is an endogenous reducing agent and it acts as a free radical scavenger [35]. $\mathrm{N}$-acetylcysteine, with its antioxidant features, is thought to be a potential treatment agent of cadmium toxicity in leydig cells. Cadmium is a toxic agent for testes. A large amount of the world population is exposed to cadmium through respiration, nutrition and water as it is found in pesticides, cigarettes and certain nutrients. It causes irreparable damage in sertoli cells, blood-testis barrier integrity deterioration, lipid peroxidation, DNA fragmentation, testicular weight loss, antioxidant barrier system deterioration, sperm motility loss and abnormal sperm morphology increase [53]. In a study done on patients with idiopathic infertility, $600 \mathrm{mg}$ of NAC was given daily to the intervention group for 3 months and a significant change in sperm volume, motility and semen viscosity was detected [54]. In another study done on infertile OAT men, a treatment of $200 \mathrm{mg}$ of selenium, $600 \mathrm{mg}$ of acetylcystein and a combined treatment of both was applied daily. As a result of this combined treatment, serum FSH decreased and a significant increase was found in serum testosterone, inhibin B and all semen parameters [35].

\section{Female Infertility}

To be able to get pregnant women have to have proper ovary, fallopian tube and uterus functions. Any situation that will affect these organs may lead to female infertility. Fertility in women keeps declining due to causes such as old age, smoking, excessive consumption of alcohol, being too fat and being exposed to physical or emotional stress that result in amenore. With old age women experience problems such as less ovary activation, less ovarian reserve, unhealthy ova, health problems that may lead to fertility problems and an increase in the possibility of miscarriage, and these all lead to infertility [3]. Nearly one third of couples experience fertility problems when women are over 35 and miscarriage rate between the ages $25-29$ is $10 \%$, while it is $18 \%$ between the ages 30-35 and this rate is 35\% and over for women over the age of 40 [55].

\section{The Relationship between Obesity and Infertility}

As obesity is becoming more and more common, it is regarded as an epidemic and is related to anovulation experienced by women in reproductive period, irregular menstruation, subfertility, miscarriage and many types of reproductive sequelae including negative pregnancy results. These reproductive sequelae result from the effects of obesity on the regeneration of ovarian follicles, oocyte development and quality, oocyte fertilization, embryo development and regeneration. Adipose tissues and gonads are correlated. Gonadal function in adipose tissues takes place by the release of certain adipokines such as leptin, adiponectin, ghrelin and resistin. Among these adipokines leptin is the one that is most commonly studied [56]. Leptin receptors are stated to be found in hypothalamus, gonadotrope cells of pituitary gland, granulosa, in interstitial cells of theca and ovarium and in endometrium and leydig cells [57]. The function of leptin in reproductive system includes effects such as early ovarian hyperstimulation, regulation of its development, stimulating effects of hypothalamic-pituitary-gonadal axis and inhibiting effects on developing ovarian follicles. Furthermore, leptin also suppresses the estradiol synthesis of granulosa cells with its luteinizing hormone stimulation. These effects partly explain the reason why obese women have insufficient reproductive performance [56]. Obese women, especially android obese women, have resistance to insulin, hyperinsulinemia, hyperandrogenemia and an increase in aromatization of 
androgens to estrogens in peripheral tissues. Besides, obesity causes a change in gonadotropin release (GnRH), a decrease in the levels of sex hormone binding globulin (SHBG), growth hormone and insulin-like growth factor proteins, an increase in leptin levels and transformation of hypothalamic-pituitary-gonadal axis neuroregulation [58]. By the increase of insulin resistance and hyperinsulinemia, sex hormone binding globulin synthesis decreases in the liver. As a result of this, free androgen circulation increases and its aromatization increases the circulation of free estrogen. Estrogen suppresses the follicle stimulating hormone (FSH) which is released from the pituitary gland [59]. As BMI increases, the levels of sex hormone and sex hormone binding globulin decrease in women while the increase of parameters such as insulin, plasma androgens, leptin and luteinizing hormones $(\mathrm{LH})$ cause anovulation ${ }^{(12 ; 61)}$. In obese women, irregular menstrual cycle is twice as common as compared to women with normal body weight. Moreover, body composition measurements were proved to be positively related to fasting insulin and testosterone levels and negatively related to SHBG [60]. In a study done on women who received in vitro fertilization (IVF) treatment basal LH, FSH and estradiol levels were found to be higher in women with normal body weight, whereas overweight and obese women were reported to need higher levels of gonadotropin to gain an equal ovarian response as women with normal body weight. No significant difference was found between treatment results. However, in the overweight and obese group transfer rejection and miscarriage levels were more common [61]. In another study done on overweight and obese infertile women, it was stated that with more than $10 \%$ weight loss, the rates of pregnancy and live birth increased dramatically [62]. A study done with women who had embryo transfer showed that the rates of insemination, pregnancy, clinical pregnancy, twin pregnancy and live birth decreased significantly when BMI increased [63]. Schliep et al., (2015) couldn't find a significant relationship between BMI increase and fertilization, embryo score and pregnancy incidence in couples receiving IVF treatment when compared to a group with normal body weight [64]. on the other hand, stated that pregnancy rate of overweight and obese women was $23 \%$ at the end of the treatment and it was $42 \%$ in the group with normal body weight. Nevertheless, they couldn't find any relationship between temporary weight loss and rates of clinical pregnancy and live birth $[65,66]$.

\section{Polycystic Ovary Syndrome and Infertility}

Polycystic ovary syndrome (PCOS) is a health problem which may lead to anovulatory infertility due to metabolic disorders such as obesity, insulin resistance, abnormal release of gonad hormone together with menstrual disorders, hyperandrogenism and hirsutism [67,68]. A study showed that obesity and applying assisted reproductive techniques is more common among women who have PCOS compared to the ones who don't [68]. Improving healthy life factors of infertile, anovulatory, obese women who have PCOS (by a long-term diet which prevents rapid weight loss and includes regular physical activities) were able to ovulate again; in addition, an $11 \%$ of increase was reported in their abdominal obesity, a $33 \%$ of increase was reported in their fasting blood glucose, a 39\% of decrease was reported in their LH levels and a 71\% of increase was reported in their insulin sensitivity [69].

\section{Nutritional Pattern and Infertility}

In a study which analyzed the nutritional pattern of infertile women, it was stated that $16 \%$ of their daily energy is gained from protein, $33 \%$ of it is gained from fat and $52 \%$ of it is gained from carbohydrates and their fiber consumption is low. A low glysemic index and energy diet was applied for 12 weeks on infertile, obese and overweigt women who experienced IVF and as a result, they were claimed to have lower BMI, rate of waist/ hip and leptin levels; whereas $85 \%$ higher oocyte numbers compared to the group who didn't follow a diet [71]. In a study conduct on rats following a western diet, it was stated that this diet caused obesity and hyperglycemia; it also changed the ovarian functions and decreased the ovarian reserve. While the diestrus phase got longer in these rats, decreased estradiol level and follicular cysts were spotted [72]. Fatty diet consumption was reported to reduces folliculogenesis in the primordial and Graafian stages, in vitro maturation and in vitro fertilisation rates, as well as oocyte quality [73]. determined that the diet of women who got pregnant as a result of IVF treatment consist of higher levels of PUFA; especially n-6 PUFA and linoleic acid and n-3 [74]. Chevarro and friends stated that the consumption of animal based proteins increased the risk of anovulatory infertility. Consumption of plant based proteins instead of $5 \%$ of the amount of energy that is gained from carbohydrates decreases the risk of infertility $43 \%$, and the consumption of plant based proteins instead of animal proteins decreases the risk of infertility $50 \%$ [65].

\section{The Relationship between Certain Vitamins and Infertility}

Folic Acid: Folate deficiency is related to decreases in cell division, methylation reaction dysfunction and increases in inflammatory cytokine production, oxidative stress and apoptosis in the metabolism. All of these affect oocyte development and as a result, fertility in women [75]. Insufficient folate intake was reported to cause the luteal progesterone levels to decrease and the risk of anovulation to increase [76]. According to a study done on women in reproductive period, folate supplement decreases the risk of ovulatory infertility [75]. In another cohort study done on women who received IVF treatment, women who were supplemented with folic acid had healthier oocytes compared to the women who didn't and they had more mature oocytes compared to them [76]. An intake of $700 \mu \mathrm{g}$ of folic acid daily was reported to be effective on ovary caused infertility and increase the rate of pregnancy $40-50 \%$ [77]. For this reason, women planning pregnancies are supplemented with folic acid. 
MYO-Inositol and D-Chiro Inositol: Myo-inositol (MI) and D-chiro-inositol are isoforms of inositol and they belong to the class of vitamin B complex. While myo-inositol is a common natural substance, its epimer D-chiro inositol is rarely found [78]. Inositol isoforms are used for the continuity of ovulation and oocyte maturation, for treatment purposes. These isoforms decrease the androgen production in theca cells and affect steroidogenesis directly and by increasing the insulin sensitivity in patients with PCOS, they develop ovulatory function [79]. D-chiro inositol causes a decrease in the serum testosterone levels, an increase in ovulation, and it has positive effects on parameters such as the blood pressure and triglyceride of women with PCOS. In a study done on women who were supplemented with D-chiro inositol, it was reported that their ovulation frequency doubled and their serum HDL concentration and insulin sensitivity increased [80]. When a study group of only myo-inositol users and a group of myo-inositol and D-chiro inositol combined users are compared, in the group who received a combined treatment, a significant decrease in the total testosterone levels and a significant increase in the SHBG were found at the end of a 6-month treatment [5,81-85].

\section{Results and Recommendations}

The prevalence of infertility has been increasing significantly nowadays. There are several studies suggesting that this increasing prevalence results from life style, nutritional habits and environmental factors. While male infertility is known to be related to the relationship between oxidative stress and antioxidants, female infertility is known to be closely related to insulin resistance and the effects of PCOS. BMI, on the other hand, sets the stage for infertility for both sexes.

It is hard to reach certain conclusions on pregnancy results and rates of live birth in terms of the relationship between nutrition and infertility, as there are few studies on this subject. Besides, due to the differences between the planning and assessment of these studies, there are some contradictions among them. It would be useful for the individuals with infertility problems to eat sufficiently and have a balanced and healthy diet, include a variety of nutrients in their diet -especially food that contain antioxidants-, prefer seasonal vegetables and fruit that do not contain pesticide residues and be careful with their consumption of caffeine. In addition to applying the general principles of healthy nutrition, it would be beneficial for them to do regular physical activities to prevent obesity and insulin resistance.

\section{References}

1. WHO (2016) Sexual and reproductive health-Infertility Definitions and Terminology. Geneva, Switzerland.

2. Dohle GR, Colpi GM, Hargreave TB, Papp GK, Jungwirth A, et al. (2005) EAU guidelines on male infertility. Eur Urol 48: 703-11.

3. CDC (2017) Reproductive Health and Infertility FAQs. Clifton Road Atlanta, GA, USA.

4. Barrett K, Barman S, Boitano S, Brooks H (2011) In: Gökbel H Ganong’un tıbbi fizyolojisi (Çeviri Editörü) 23. Bask1, İstanbul: Nobel Tip Kitabevleri, 550.

5. Sanlier N (2010) Beslenme alışkanlıklarının üreme sağlığı üzerine etkileri.Çevrenin Erkek Cinsel ve Üreme Sağlığına Etkisi ve Korunma Yolları. Türk Androloji Derneği Yayınları.

6. Cayan S, Özdemir A, Orhan İ, Altay B, Kadığlu A (2015) Oksidatif stresin fertilitiye etkisi ve infertil erkeklerde anti-oksidan tedavinin yeri. Bülteni 17: 118-24.

7. Ramalingam M, Kini S, Mahmood T (2014) Male fertility and infertility. Obstet Gynaecol Reprod Med 24: 326-32.

8. Demirci N (2014) Erkek Fertilitesi ve Riskli Yaşam Biçimi Davranışları. Florence Nightingale Hemşirelik Dergis 22: 39-45.

9. Oliva A, Spira A, Multigner L (2001) Contribution of environmental factors to the risk of male infertility. Hum Reprod 16: 1768-76.

10. Aggerholm AS, Thulstrup AM, Toft G, Ramlau-Hansen CH, Bonde JP (2008) Is overweight a risk factor for reduced semen quality and altered serum sex hormone profile? Fertil Sterili 90: 619-26.

11. Pauli EM, Legro RS, Demers LM, Kunselman AR, Dodson WC (2008) Diminished paternity and gonadal function with increasing obesity in men. Fertil Steril 90: 346-51.

12. Yllmaz FÇ, Yardımcı H (2015) Beden Kütle İndeksinin İnfertilite Üzerine Etkisi. Hacettepe University Faculty of Health Sci J 2: 1.

13. Sermondade N, Faure C, Fezeu L, Lévy R, Czernichow S (2012) Obesity and increased risk for oligozoospermia and azoospermia. Arch Intern Med 172: 440-2.

14. Sermondade N, Faure C, Fezeu L, Shayeb AG, Bonde JP, et al. (2013) BMI in relation to sperm count: an updated systematic review and collaborative metaanalysis. Hum Reprod Update 19: 221-31

15. Dupont C, Faure C, Sermondade N, Boubaya M, Eustache F, et al. (2013) Obesity leads to higher risk of sperm DNA damage in infertile patients. Asian J Androl 15: $622-5$.

16. Bandel I, Bungum M, Richtoff J, Malm J, Axelsson J, et al. (2015) No association between body mass index and sperm DNA integrity. Hum Reprod 30: 1704-13.

17. Braga DP, Halpern G, Figueira Rde C, Setti AS, Iaconelli A, et al. (2012) Food intake and social habits in male patients and its relationship to intracytoplasmic sperm injection outcomes. Fertil Steril 97: 53-9.

18. Liu CY, Chou YC, Chao JC, Hsu CY, Cha TL, et al. (2015) The association between dietary patterns and semen quality in a general Asian population of 7282 Males. PLoS One 10: e0134224.

19. Jensen TK, Heitmann BL, Blomberg Jensen M, Halldorsson TI, Andersson AM, et al. (2013) High dietary intake of saturated fat is associated with reduced semen quality among 701 young Danish men from the general population. Am J Clin Nutr 97: 411-8.

20. Ko EY, Sabanegh ES (2014) The role of nutraceuticals in male fertility. Urol Clin North Am 41: 181-93.

21. Colagar AH, Pouramir M, Marzony ET, Jorsaraei SGA (2009) Relationship between Seminal Malondialdehyde Levels and Sperm Quality in Fertile and Infertile Men. Braz Arch Biol Techn 52: 1387-92.

22. Safarinejad MR, Hosseini SY, Dadkhah F, Asgari MA (2010) Relationship of omega-3 and omega- 6 fatty acids with semen characteristics, and anti-oxidant status of seminal plasma: a comparison between fertile and infertile men. Clin Nut 29: 100-5. 
23. Zararsız I, Kuş I, Davarcı M, Abdulgani Kuş M, Kaman D, et al. (2011) The protective effects of omega-3 fatty acids on rat testicular tissue. Dicle Med J $38: 382-6$. 24. Sikka SC, Rajasekaran M, Hellstrom WJ (1995) Role of oxidative stress and antioxidants in male infertility. J Androl 16: 464-8.

25. Vijayprasad S, Bb G, Bb N (2014) Effect of vitamin C on male fertility in rats subjected to forced swimming stress. J Clin Diagn Res 8: HC05-8.

26. Wong WY, Merkus HM, Thomas CM, Menkveld R, Zielhuis GA, et al. (2002) Effects of folic acid and zinc sulfate on male factor subfertility: a double-blind, randomized, placebo-controlled trial. Fertil Steril 77: 491-8.

27. Vujkovic M, de Vries JH, Dohle GR, Bonsel GJ, Lindemans J, et al. (2009) Associations between dietary patterns and semen quality in men undergoing IVF/ ICSI treatment. Hum Reprod 24: 1304-12.

28. Eskenazi B, Kidd SA, Marks AR, Sloter E, Block G, et al. (2005) Antioxidant intake is associated with semen quality in healthy men. Hum Reprod 20: 1006-12. 29. Wong WY, Merkus HM, Thomas CM, Menkveld R, Zielhuis GA, et al. (2002) Effects of folic acid and zinc sulfate on male factor subfertility: a double-blind, randomized, placebo-controlled trial. Fertil Steril 77: 491-8.

30. Vujkovic M, de Vries JH, Dohle GR, Bonsel GJ, Lindemans J, et al. (2009) Associations between dietary patterns and semen quality in men undergoing IVF/ ICSI treatment. Hum Reprod 24: 1304-12.

31. Ebisch IM, Pierik FH, DE Jong FH, Thomas CM, Steegers-Theunissen RP (2006) Does folic acid and zinc sulphate intervention affect endocrine parameters and sperm characteristics in men? Int J Androl 29: 339-45.

32. Young SS, Eskenazi B, Marchetti FM, Block G, Wyrobek AJ (2008) The association of folate, zinc and antioxidant intake with sperm aneuploidy in healthy non-smoking men. Hum Reprod 23: 1014-22.

33. Raigani M, Yaghmaei B, Amirjannti N, Lakpour N, Akhondi MM (2014) The micronutrient supplements, zinc sulphate and folic acid, did not ameliorate sperm functional parameters in oligoasthenoteratozoospermic men. Andrologia 46: 956-62.

34. Lanzafame FM, La Vignera S, Vicari E, Calogero AE (2009) Oxidative stress and medical antioxidant treatment in male infertility. Reprod Biomed Online 19: 638-59.

35. Safarinejad MR (2009) Efficacy of coenzyme Q10 on semen parameters, sperm function and reproductive hormones in infertile men. J Urol 182: 237-48.

36. Safarinejad MR (2012) The effect of coenzyme Q10 supplementation on partner pregnancy rate in infertile men with idiopathic oligoasthenoteratozoospermia: an open-label prospective study. Int Urol Nephrol 44: 689-700.

37. Lafuente R, González-Comadrán M, Solà I, López G, Brassesco M, et al. (2013) Coenzyme Q10 and male infertility: a meta-analysis. J Assist Reprod Genet 30: $1147-56$.

38. Cakiroglu B, Eyyupoglu SE, Gozukucuk R, Uyanik BS (2014) Ubiquinol effect on sperm parameters in subfertile men who have astheno-teratozoospermia with normal sperm concentration. Nephrourol Mon 10: e16870.

39. Thakur AS, Littarru GP, Funahashi I, Painkara US, Dange NS, et al. (2015) Effect of Ubiquinol Therapy on Sperm Parameters and Serum Testosterone Levels in Oligoasthenozoospermic Infertile Men. J Clin Diagn Res 9: BC01-3.

40. Keskes-Ammar L, Feki-Chakroun N, Rebai T, Sahnoun Z, Ghozzi H (2003) Sperm oxidative stress and the effect of an oral vitamin E and selenium supplement on semen quality in infertile men. Arch Androl 49: 83-94.

41. Moslemi MK, Tavanbakhsh S (2011) Selenium-vitamin E supplementation in infertile men: effects on semen parameters and pregnancy rate. Int J Gen Med 4: 99-104.

42. Scott R, MacPherson A, Yates RW, Hussain B, Dixon J (1998) The effect of oral selenium supplementation on human sperm motility. Br J Urol 82: 76-80.

43. Mistry HD, Broughton Pipkin F, Redman CW, Poston L (2012) Selenium in reproductive health. Am J Obstet Gynecol 206: 21-30.

44. Yao DF, Mills JN (2016) Male infertility: lifestyle factors and holistic, complementary, and alternative therapies. Asian J Androl 18: 410-8.

45. Jensen TK, Swan SH, Skakkebaek NE, Rasmussen S, Jørgensen N (2010) Caffeine intake and semen quality in a population of 2,554 young Danish men. Am J Epidemiol 171: 883-91

46. Oldereid NB, Rui H, Purvis K (1991) Life styles of men in barren couples and their relationship to sperm quality. Int J Fertil 37: 343-9.

47. Ramlau-Hansen CH, Thulstrup AM, Bonde JP, Olsen J, Bech BH (2008) Semen quality according to prenatal coffee and present caffeine exposure: two decades of follow-up of a pregnancy cohort. Hum Reprod 23: 2799-805.

48. Sobreiro BP, Lucon AM, Pasqualotto FF, Hallak J, Athayde KS, et al. (2005) Semen analysis in fertile patients undergoing vasectomy: reference values and variations according to age, length of sexual abstinence, seasonality, smoking habits and caffeine intake. Sao Paulo Med J 123: 161-6.

49. Wesselink AK, Wise LA2, Rothman KJ3, Hahn KA4, Mikkelsen EM, et al. (2016) Caffeine and caffeinated beverage consumption and fecundability in a preconception cohort. Reprod Toxicol 62: 39-45.

50. Zhou X, Liu F, Zhai S (2007) Effect of L-carnitine and/or L-acetyl-carnitine in nutrition treatment for male infertility: a systematic review. Asia Pac J Clin Nutr 16: 383-90.

51. Lenzi A, Sgrò P, Salacone P, Paoli D, Gilio B, et al. (2004) A placebo-controlled double-blind randomized trial of the use of combined L-carnitine and l-acetylcarnitine treatment in men with asthenozoospermia. Fertil Steril 81: 1578-84.

52. Balercia G, Regoli F, Armeni T, Koverech A, Mantero F, et al. (2005) Placebo-controlled double-blind randomized trial on the use of L-carnitine, L-acetylcarnitine, or combined L-carnitine and L-acetylcarnitine in men with idiopathic asthenozoospermia. Fertil Steril 84: 662-71.

53. Lamas CA, Gollücke AP, Dolder H (2015) Grape juice concentrate $\left(\mathrm{G} 8000^{\circ}\right)$ intake mitigates testicular morphological and ultrastructural damage following cadmium intoxication. Int J Exp Pathol 96: 301-10.

54. Ciftci H, Verit A, Savas M, Yeni E, Erel O (2009) Effects of N-acetylcysteine on semen parameters and oxidative/antioxidant status. Urology 74: 73-6.

55. Serdaroğlu H (2004) In: Ankara: Nobel Tip Kitabevi. Jinekoloji 261.

56. Metwally M, Li TC, Ledger WL (2007). The impact of obesity on female reproductive function. Obes Rev 8: 515-23.

57. Moschos S, Chan JL, Mantzoros CS (2002) Leptin and reproduction: a review. Fertil Steril 77: 433-44.

58. Parihar M (2003) Obesity and infertility. Rev Obstet Gynecol 3: 120-6.

59. Best D, Bhattacharya S (2015) Obesity and fertility. Horm Mol Biol Clin Investig 24: 5-10.

60. Wei S, Schmidt MD, Dwyer T, Norman RJ, Venn AJ (2009) Obesity and menstrual irregularity: associations with SHBG, testosterone, and insulin. Obesity 17: $1070-6$. 
61. Caillon H, Fréour T, Bach-Ngohou K, Colombel A, Denis MG (2015) Effects of female increased body mass index on in vitro fertilization cycles outcome. Obes Res Clin Pract 9: 382-8.

62. Kort JD, Winget C, Kim SH, Lathi RB (2014) A retrospective cohort study to evaluate the impact of meaningful weight loss on fertility outcomes in an overweight population with infertility. Fertil Steril 101: 1400-3.

63. Bellver J, Pellicer A, García-Velasco JA, Ballesteros A, Remohí J, et al. (2013) Obesity reduces uterine receptivity: clinical experience from 9,587 first cycles of ovum donation with normal weight donors. Fertil Steril 100: 1050-8.

64. Schliep KC, Mumford SL, Ahrens KA, Hotaling JM, Carrell DT, et al. (2015) Effect of male and female body mass index on pregnancy and live birth success after in vitro fertilization. Fertil Steril 103: 388-95.

65. Chavarro JE, Rich-Edwards JW, Rosner BA, Willett WC (2009) A prospective study of dietary carbohydrate quantity and quality in relation to risk of ovulatory infertility. Eur J Clin Nutr 63: 78-86.

66. Maru S, van der Schouw YT, Gimbrère CH, Grobbee DE, Peeters PH (2004) Body mass index and short-term weight change in relation to mortality in Dutch women after age 50 y. Am J Clin Nutr 80: 231-6.

67. Franks S (1995) Polycystic ovary syndrome. N Engl J Med 333: 853-61.

68. Roos N, Kieler H, Sahlin L, Ekman-Ordeberg G, Falconer H, et al. (2011) Risk of adverse pregnancy outcomes in women with polycystic ovary syndrome: population based cohort study. BMJ 343: d6309.

69. Huber-Buchholz MM., Carey D, Norman R, (1999) Restoration of Reproductive Potential by Lifestyle Modification in Obese Polycystic Ovary Syndrome: Role of Insulin Sensitivity and Luteinizing Hormone. J Clin Endocrinol Metab 84: 1470-4.

70. Colombo O, Pinelli G, Comelli M, Marchetti P, Sieri S, et al. (2009) Dietary intakes in infertile women a pilot study. Nutr J 8: 53.

71. Becker GF, Passos EP, Moulin CC (2015) Short-term effects of a hypocaloric diet with low glycemic index and low glycemic load on body adiposity, metabolic variables, ghrelin, leptin, and pregnancy rate in overweight and obese infertile women: a randomized controlled trial. Am J Clin Nutr 102: 1365-72.

72. Bazzano M, Torelli C, Pustovrh MC, Paz D, Elia EM (2015) Obesity induced by cafeteria diet disrupts fertility in the rat by affecting multiple ovarian targets. Reprod Biomed Online 31: 655-67.

73. Sohrabi M, Roushandeh AM, Alizadeh Z, Vahidinia A, Vahabian M, et al. (2015) Effect of a high fat diet on ovary morphology, in vitro development, in vitro fertilisation rate and oocyte quality in mice. Singapore Med J 56: 573-9.

74. Moran LJ, Tsagareli V, Noakes M, Norman R (2016) Altered Preconception Fatty Acid Intake Is Associated with Improved Pregnancy Rates in Overweight and Obese Women Undertaking in Vitro Fertilisation. Nutrients 8: E10.

75. Altmäe S, Stavreus-Evers A, Ruiz JR, Laanpere M, Syvänen T, et al. (2010) Variations in folate pathway genes are associated with unexplained female infertility. Fertil Steril 94: 130-7.

76. Tremellen K, Pearce K (2015) In: Nutrition, Fertility and Human Reproductive Function. CRC Press, New York, USA.

77. Bennington LK (2010) Can complementary/alternative medicine be used to treat infertility? MCN Am J Matern Child Nurs 35: 140-7.

78. Yoshida K, Yamaguchi M, Morinaga T, Ikeuchi M, Kinehara M (2006) Genetic modification of Bacillus subtilis for production of D-chiro-inositol, an investigational drug candidate for treatment of type 2 diabetes and polycystic ovary syndrome. Appl Environ Microbiol 72: 1310-5.

79. Papaleo E, Unfer V, Baillargeon JP, Fusi F, Occhi F, et al. (2009) Myo-inositol may improve oocyte quality in intracytoplasmic sperm injection cycles. A prospective, controlled, randomized trial. Fertil Steril 91: 1750-4.

80. Unfer V, Carlomagno G, Rizzo P, Raffone E, Roseff S (2011) Myo-inositol rather than D-chiro-inositol is able to improve oocyte quality in intracytoplasmic sperm injection cycles. A prospective, controlled, randomized trial. Eur Rev Med Pharmacol Sci 15: 452-7.

81. Nordio M, Proietti E (2012) The combined therapy with myo-inositol and D-chiro-inositol reduces the risk of metabolic disease in PCOS overweight patients compared to myo-inositol supplementation alone. Eur Rev Med Pharmacol Sci 16: 575-81.

82. Colagar AH, Marzony ET, Chaichi MJ (2009) Zinc levels in seminal plasma are associated with sperm quality in fertile and infertile men. Nutr Res 29: 82-8.

83. Safarinejad MR, Safarinejad S (2009) Efficacy of selenium and/or N-acetyl-cysteine for improving semen parameters in infertile men: a double-blind, placebo controlled, randomized study. J Urol 181: 741-51.

84. Safarinejad MR, Safarinejad S, Shafiei N, Safarinejad S (2012) Effects of the reduced form of coenzyme Q 10 (ubiquinol) on semen parameters in men with idiopathic infertility: a double-blind, placebo controlled, randomized study. J Urol 188: 526-31.

85. WHO (2010) In: WHO laboratory manual for the Examination and processing of human sperm (5 $5^{\text {th }}$ Edn). Geneva, Switzerland.

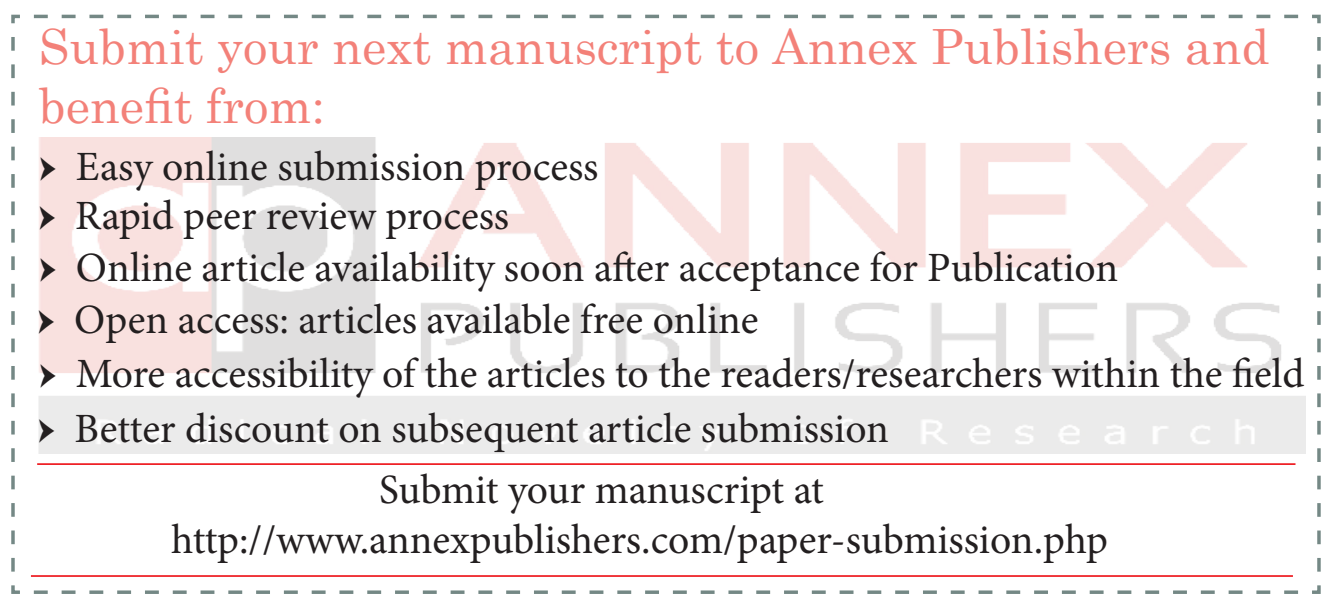

